\title{
AC 2007-896: THE TSUNAMI MODEL ELICITING ACTIVITY: IMPLEMENTATION AND ASSESSMENT OF AN INTERDISCIPLINARY ACTIVITY IN A PRE-ENGINEERING COURSE
}

\section{Kenneth Reid, Indiana University-Purdue University-Indianapolis}

Kenneth Reid is an Associate Professor in Electrical and Computer Engineering Technology. He has a BS in Computer and Electrical Engineering from Purdue University, and an MSEE from Rose-Hulman Institute of Technology. He is currently pursuing a Ph.D. in Engineering Education at Purdue University and working to assess success in first year engineering technology students and implement advanced digital design techniques into early digital courses.

\section{Christine Floyd, Brownsburg East Middle School}

Chris Floyd has been teaching in Brownsburg for 7 years, with the past 5 years at the middle school level. She has been instrumental in piloting and promoting the Project Lead the Way Gateway to Technology program for Brownsburg. In addition to serving as Technology Education Department head, Chris is currently a member of the TECCA (Technology Education Curriculum Crosswalk Activity) project working with the Indiana Department of Education to develop technology activities for the State, and is the IEEE Pre-College Engineering Committee K-12 Liaison. 


\title{
The Tsunami Model Eliciting Activity: Implementation and Assessment of an Interdisciplinary Activity in a Pre-Engineering Course
}

\begin{abstract}
This paper describes an interdisciplinary pre-engineering activity which was designed and implemented in a seventh grade pre-engineering course. The activity was designed for implementation in combination with Social Studies and Science classes. The activity is a Model Eliciting Activity (MEA) where students develop a model to specify requirements and costs for emergency housing after a large scale natural disaster - in this case, the 2004 tsunami. The activity and implementation plan are described in detail. The activity was tied to Indiana state standards in English, Mathematics, Social Studies and Science. This alignment to standards is discussed.

A qualitative assessment was done after the initial implementation. This assessment focused on two areas including student perception of the activity and changes in student perception of engineering. The results showed that students found the activity valuable and the project enhanced their perception of engineers and engineering as a profession. This initial assessment consisted of student interviews; the answers were evaluated specifically assessing student impressions of the activity itself, the activity in relation to engineering and cultural factors (ie: Social Studies), and changes in student perception of engineering. The paper presents results of these assessments showing the effectiveness of the activity. Results from a post activity survey are included to validate the findings from the student interviews.
\end{abstract}

\section{Introduction:}

"Education in science, mathematics, and technology has become a focus of intense concern within the business and academic communities. The domestic and world economies depend more and more on science and engineering. But our primary and secondary schools do not seem able to produce enough students with the interest, motivation, knowledge, and skills they will need to compete and prosper in such a world.". 1

The results of a society strong in engineering are obvious: automobiles, air travel, telephone and power networks, cell phones, the Internet, MP3 players, and numerous other examples. The National Academies Press report "Rising Above The Gathering Storm: Energizing and Employing America for a Brighter Economic Future" describes the importance of advances in engineering and technology as crucial to the social and economic conditions and discusses changes that must occur in the K-12 education system to promote engineering and technology for the United States to compete, prosper, and be secure in the global community in the $21^{\text {st }}$ century. However, middle school students are often unaware of the engineering profession; those students who are aware of engineering often misunderstand the role of engineers in society. 


\section{Perceptions of Engineering in Middle School:}

Current studies of perceptions of engineering in middle school show that students typically lack the most basic knowledge of engineering and what engineers do. Cunningham ${ }^{2}$ worked with students in first through fifth grades, and found that a large majority of students believed that engineers worked on cars. Fewer than one third of students identified design as a characteristic of engineering.

A metanalysis of various "draw an scientist" projects ${ }^{3}$ shows when students are asked to draw a scientist and characteristics of the drawings assessed to determine characteristics of their perceptions of scientists, these pictures include many stereotypical results: engineers are usually portrayed as male, working in a laboratory wearing white lab coats. In one study involving the development and use of a similar Draw an Engineer Test ${ }^{4}$, many initial misconceptions included engineers as primarily train drivers or auto mechanics. Most student responses involved engineers building buildings or fixing car engines, and were nearly all male. This perception is most likely one factor contributing to a very low percentage of female engineering students.

\section{Model Eliciting Activities:}

Model Eliciting Activities (MEAs) are specifically designed as client driven, open ended problems. The goal of the activity is to design a model with transferability rather than a single solution, a concept not typically found in middle school problems. MEAs lack structure found in typical problems through K-12 with a variety of acceptable solutions rather than a single solution. MEAs are designed to adhere to the following principles ${ }^{5,6,7,8}$ :

1. The Model Construction Principle requires activities in which students develop a mathematical model. This principle ensures that students experience the design of a product or process using existing knowledge and concepts.

2. The Reality Principle requires the problem be presented in a context based in reality to allow the learners to relate their development to a real life issue. The solution generated must also be a realistic, feasible solution.

3. The Self-Assessment Principle requires that the students or student teams be able to assess their progress through the development of their model. The problem must include sufficient data and context to allow the students to judge for themselves when a model is working or if it requires modification.

4. The Model Documentation principle requires students to document their progress as well as their final model. The development of the final product - the model - is a deliverable in itself. This allows students' to look reflectively as they continue development of the model.

5. The Share-ability / Reusability / Generalizability Principle requires a solution that can apply not only to the situation as presented, but is applicable to similar situations. The solution should also be transferable to other groups working on the same problem.

6. The Effective Prototype Principle requires the students to test their solution given data applicable to the client's problem as presented. Their model should work with sample data supplied by the client to demonstrate that their solution is feasible. 
MEAs have been studied in first year engineering programs. Students involved in these activities have reported teaming, engineering context and problem solving as items they learned from MEAs that will have positive effects on their academic and professional careers ${ }^{9}$.

Developing effective MEAs requires continuous review of the six principles and the anticipation of the variety of possible solutions that may be developed.

An examination of curricula by the National Academies indicates "middle-school mathematics and science courses lack focus, cover too many topics, repeat material, and are implemented inconsistently" ". New educational standards emphasizing inquiry and/or specifying engineering or technology as necessary topics, as well as the acceptance of pre-engineering curricula such as Project Lead the Way ${ }^{11}$ may help improve math curriculum in secondary schools. Project Lead the Way and similar curricula allow schools to adapt pre-engineering courses within the scope of state standards ${ }^{12}$.

Programs introduced into the curriculum must be correlated to state educational standards to be most useful to teachers. If programs are not tied to standards, they are unlikely to be implemented into already crowded curricula. Some states (Massachusetts for example) have added engineering concepts into their state curricula, while others have technology or similar concepts. MEAs fit well into science, math, technology and engineering standards, and those designed to be interdisciplinary fit into English, social studies, etc.

\section{Theoretical Framework}

This paper presents results of a qualitative study of the implementation of a Model Eliciting Activity (MEA) into a seventh grade classroom. The activity is designed to be interdisciplinary, address a real life problem and involve the students in a scenario where engineers help society. The specific research questions are:

- What was the students' perception of the activity compared to other activities in preengineering or science courses?

- What effect did this activity have on perceptions of engineers and engineering?

Implementing a hands-on, design oriented active learning project portraying engineering as a helping profession fostered an interest in and more accurate perception of engineering. If students perceive the activity as positive and worthwhile, and the activity is designed to portray engineering as a profession that helps society and solves problems, incorporating this activity should improve the perception of middle school students (and teachers).

This viewpoint allows for the students' construction of a perception of engineering in which they have ownership, allowing their perceptions to develop through complex and relevant learning environments ${ }^{13}$. This is desirable to ensure that the perceptions last within the student instead of simply immediate short-term learning. For example, it is preferable for the student to develop an opinion of themselves in relation to engineering instead of answering multiple choice answers on what engineers do. 


\section{Educational Setting:}

This activity was implemented in the Gateway to Technology class in Brownsburg East Middle School, Brownsburg, Indiana. This is a suburban school district which has implemented the Project Lead the Way curriculum. Gateway is the introductory course to the PLTW program and is offered in seventh grade in Brownsburg's two middle schools.

There were 120 total students in the Gateway course in the fall 2006 semester at East Middle School, 60 of which were in a section of the class implementing the tsunami activity. The Gateway course was an elective for seventh grade students. The sections that participated were $67 \%$ male, $33 \%$ female. Students were placed in teams of 5-6 students per team around large tables, a typical arrangement for most projects in the class.

This initial implementation involved incorporating the entire MEA in the Gateway course; a true interdisciplinary model of the project across social studies, science and Gateway has been designed and will be implemented.

The activity was implemented over a ten day period toward the end of the semester. Student presentations were videotaped and all written work was collected (again, typical of other class projects).

\section{Methodology}

The Tsunami MEA was developed at a middle school level. The premise of the problem is a need to develop a mathematical model to specify emergency housing after a large scale natural disaster such as the tsunami in the Indian Ocean in December 2004. The activity incorporates the culture of India, discovery of the scope of natural disasters and engineering as a problem solving profession.

The following list of instructional objectives was prepared for the middle school implementation:

Students will develop an understanding of the following through this activity:

- important differences between cultural groups (castes) in Indian society

- different designs and requirements for housing in other countries

- the dynamics of designing emergency relief housing for a population

- the potential devastation caused by large scale natural disasters

- engineering is a profession involving problem solving and helping people

- the difference between the development of a model which applies to multiple scenarios and a single solution (ie: scientific inquiry)

The tsunami MEA consisted of the following steps:

1. (Social Studies) Students begin with an individual homework assignment with open ended questions on natural disasters, engineering and housing. Some example questions include:

- How are people affected by natural disasters? 
- What can engineers design to minimize the impact of natural disasters?

- Think of the smallest house you could live in. What are some things a house in the United States must have?

- Describe a house in a poor section of Africa or India: what are some things a house in this area must have?

Ideally, a coordinated science class would introduce natural disasters including tsunamis at the same time.

2a. (Social Studies) Students are given a second homework assignment: read a series of two articles based on newspaper accounts of the tsunami and inconsistent distribution of aid. A sample village begins to emerge from these readings consisting of two groups: fishermen who had their boats and homes swept away and are receiving aid, and the Dalits (formerly "Untouchables") who lost all possessions but are not receiving aid. The stories are illustrated, and some of the language was modified to be at a slightly lower level than originally published to ensure a $6^{\text {th }}-8^{\text {th }}$ grade reading level.

2b. Students are given a series of questions to answer individually as part of this homework assignment based on the reading. The questions are open ended. Some include:

- Why do the fishermen in the Indian village (from the reading) have much nicer houses than the Dalits?

- How can an engineer help solve the housing problem for this village?

3. (Social Studies) Students turn in the homework then meet in teams in class to discuss their individual answers and come to a group consensus. Groups are given a blank worksheet; the teacher describes the process of finding group consensus and the groups attempt to come to consensus on one set of answers. This activity begins a discussion of socioeconomic issues in developing countries, a theme which continues through the development of the model. The teacher may intervene in groups to keep them on task if necessary. This process was designed to take 30 minutes, but one 50-minute class period was allocated since the discussion was judged to be very productive by the teacher.

4a. (Pre-engineering or Science) The students are presented a memo from Terry "Scooter" McErlstimplemant, President, Scooter Enterprises, asking their engineering team to:

I. Decide on a list of important characteristics to consider when calculating the overall cost of supplying housing. For example, one item would be the price for a selected type of house.

II. Identify a list of the minimum specifications that must be met by the solution: for example, you might list "Each family must have their own house" or "Each house must last for < some number of $>$ years." Groups are to come to consensus. 
III. Use these lists and develop mathematical models or formulas. Groups should be able to calculate important numbers like number of people, cost per house, cost per person, etc.

IV. Test the group's model using the supplied data. Determine which type(s) of housing would make the best solution for the tsunami village. Most effective solutions may have one type of house or different types. Solutions should be designed based on your list of important items.

4b. Teams are to brainstorm to find the important characteristics which must be supplied or assumed, the characteristics of an acceptable solution, and useful formulas they may need. Some examples are given:

(number of families) $*($ cost for one family shelter $)=($ total cost to house families $)$ assuming:

- the house type chosen must hold one average sized family

- the house type must be able to last for 5 years

This brainstorming activity is designed for a 30 minute in class small group session.

5. The teacher describes the process of finding a model. The assignment which follows is:

Organize your lists and formulas from the group brainstorming activity into a sheet you could turn in to your 'boss'. This is your model.

This activity took approximately one 50 minute class period. The teacher intervened in each group to keep them on task, helping them focus on the development of the model rather than focusing on a single solution.

6. Student teams are given data on possible housing types and statistics for a sample village. The population of the fictional village includes families, single people and individual children from different castes. The students are to use this data to assess their model and make adjustments. Housing types are unique: examples include:

- Cardboard house

- Cement house

- Two different steel housing units

- An "Instant Relief House" from a kit

- Emergency relief tents

Housing information includes cost per unit, cost of shipping in quantity, capacity, and other information on durability and ability to withstand weather conditions. Some characteristics of the houses (especially prices) were changed from the original data sheets to allow for multiple correct solutions.

Models are refined and tested, and an optimal solution for the specific data supplied is found. 
This section was the most difficult to lead according to the teacher in the classroom. The students tend to focus on a single solution and can lose focus on the development of the model; the teacher routinely intervened to guide students. One technique was to mention that their solution should also work after a hurricane or tornado in the United States.

Two class periods were allocated for this activity.

7. (Joint: Social Studies and Science or Pre-engineering) Students present their findings to the class. Teachers may determine requirements for the presentations including PowerPoint or posters, single group representative or group presentations. The presentation should include at least the model, the solution for the sample data and a discussion of what role engineers play and class discussion.

The specific activities can be split between science, social studies and/or pre-engineering classes (such as Project Lead the Way's Gateway to Technology course). The specific implementation discussed in this paper was entirely in the Gateway course: the eventual intent is to distribute the activities to all three classes.

The activity has been tied to Indiana state standards ${ }^{14}$ in English (including oral presentations), mathematics, science (including scientific inquiry) and social studies. It has also been tied to national standards in technology and science.

Six students were selected for pre-interviews. These students were currently in the Gateway to Technology course and had not yet started the tsunami MEA. To enrich the understanding of the perceptions before the activity, three additional students who would enroll in the Gateway course the next semester were also interviewed. Students were selected by the classroom teacher to represent a wide range of academic ability. Four students who had completed the activity were interviewed. These interviews were transcribed in their entirety, and then the results "chunked" (or grouped into similar content areas) and emergent themes were investigated. Interviews were conducted at the school in the media center or a television studio room off of the Gateway classroom.

As expected, other questions materialized during each interview. As described in Hatch ${ }^{15}$, "Interviewers ... generate questions during the interview in response to informants' responses." This allowed for emergent themes to be explored.

Students were also given a post activity survey, where they were asked some questions on their perception of the activity. Results of the applicable items are presented here verifying the qualitative analysis. Students fill out post activity surveys on most major activities within the class including this activity, so filling in the survey itself was not out of the ordinary for students.

The analysis focused on the perception of the activity itself and the perception of engineering. The data on the other classroom activities is used in the discussion of the tsunami activity. Quotes are verbatim unless otherwise indicated: interviewer questions are italicized and interviewer notes are indicated in square brackets. 


\section{Results}

\section{Perception of the activity (overall):}

The students generally said they enjoyed the activity, although when they began to further elaborate some of their interest and enjoyment was no longer evident. Initially, all of the students said they enjoyed or were challenged by the activity:

"We had to make, like, houses or shelter for people who were involved in the tsunami and it was really challenging, but it was fun, so."

"It's really challenging, but if you just pay attention and do what you're told, then you'll have a good time"

"At first, I thought it was confusing; but then after finding more about it. I could understand how the work we were doing related to real life situations and stuff; it was pretty cool once I got used to it."

"I thought it was pretty fun I think"

Further into the interviews, it was apparent that two of the students still considered the activity interesting, while two described the activity as less than interesting:

"I'd put it at about an 8. it showed what you would want to think about the in the future if you wanted to take engineering in college and stuff, all the things you need to know to have a career."

"I thought they were cool... Like, could it really be cardboard? So I looked it up on the internet; it's pretty cool" [indicated an action that was above the requirements of the project]

[laugh] "Kinda like upper, it was fun, but wasn't horrible. I don't know, most of them were pretty good. I don't know."

What did you think about the reading beforehand? What do you remember about that? "um, nothing out of the ordinary, just normal..."

"How would I make it different? Not make it full of data and different words, using calculators, everyone in my group would have these long things of data, and they would get how many people were in the village ... what I wouldn't change is... everything else.." [suggests drastic changes to make the activity more interesting]

The first two quotes are from interviews where the student clearly showed a deeper understanding of the purposes of the activity and indicated a higher interest. These students were consistent throughout the interview in their opinion that the activity was interesting and useful. The other two students initially said the activity was fun or interesting, but during the interview, they described the activity as normal. 
Opinions of other classroom activities were examined to see if the lack of interest was generally apparent towards all activities in the class or specific to the tsunami project. Each student was asked about their favorite and least favorite activities. The students who lost some enthusiasm for the tsunami project were less enthusiastic about other class projects as well. The students each mentioned three other activities: the "invention project" involved a detailed design and construction of a model of an invention (probably the most analytical and design oriented project in the class), a "wanted poster" (one of the more artistic projects) and a "measuring project" (probably the most mechanical, least imaginative project). Three students cited the invention project as their favorite. One who didn't find the tsunami project interesting liked the measurement project because the invention project was too hard:

What did you do?

We did a hot chocolate maker that came up with marshmallows...

You didn't make a working model?

No \{giggling \}

What did you think of it?

I thought it was a little hard

This student enjoyed the measurement activity the most, while the others cited it as their least favorite.

I liked it... I liked making the 3-D thing ... You had to measure it then enter it in the computer

You had to measure it then draw it?

You had to measure the block, then you had to trace it, then got to go to the computer, you ... you ... oh yeah, you made the line, then you made it have a line, then you put it on the table...

Overall, although all students initially claimed the project was fun and interesting, only two continued to describe the activity as interesting or fun.

Students in this course take post-activity surveys after most activities, including the tsunami MEA activity. Most questions ask how difficult and interesting each individual item was, or questions about the group coming to consensus. Student post-activity surveys for this activity included four Likert scale questions (rated on a scale of 5 [very] to 1 [not at all]) on the overall activity:

1) Was this activity more enjoyable than a regular class activity?

2) Was this activity more interesting than a regular class activity?

3) This activity was fun:

4) This activity was useful:

Figure 1 shows the majority of students rated the activity more enjoyable than $79 \%$ with a 4 or 5 ) and more interesting than (75\%) a regular class activity, while $70 \%$ used 4 or 5 to rate the activity was fun and useful. 
Responses to questions on usefulness and enjoyment

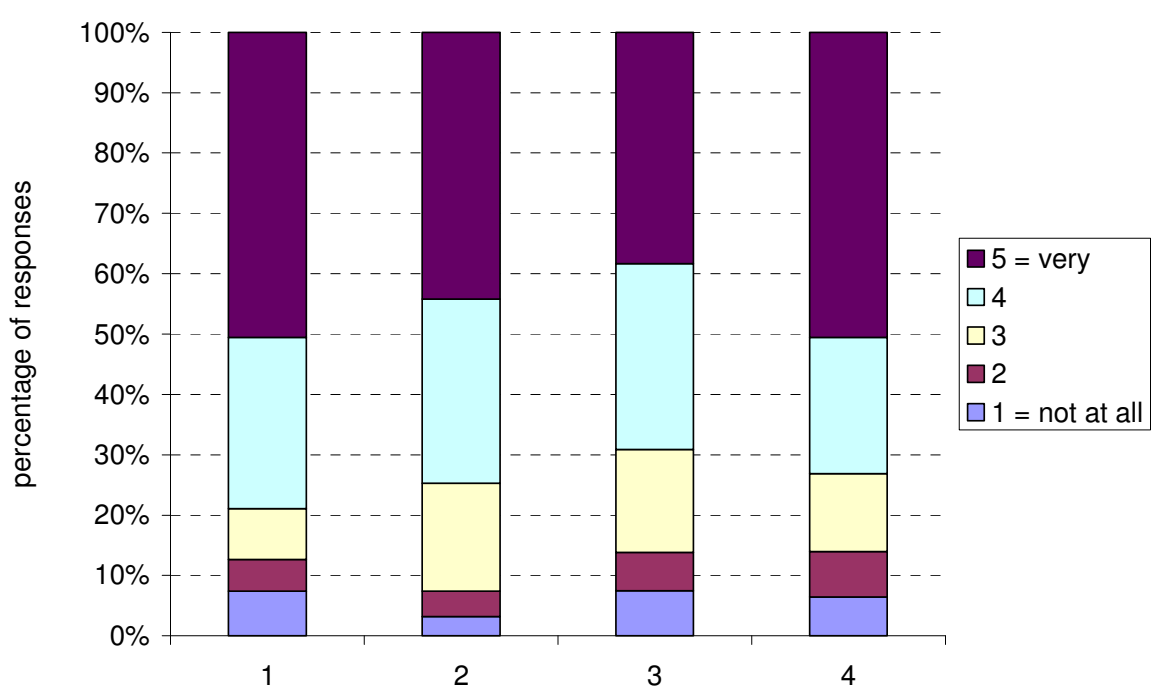

Figure 1: Percentage of responses on four items of interest

Perception of the activity (related to engineering / social studies):

All of the students were asked why we had them do this activity, and all recognized its connection to engineering and social studies. The $7^{\text {th }}$ grade Social Studies class curriculum includes India, so they were exposed to some of the same background information in two courses.

The students seemed to make a strong connection between this activity and their social studies class:

"Yeah, yeah, nothing really different - in global studies we talked more in depth about India - like instead of reading one paper, we read an entire chapter"

"These told more about the people, and global studies told more about like what already happened, what's happening, yeah"

"They were sad about all the natural disasters, but then I thought of all the things engineers have to do to prepare for rebuilding and manufacturing and stuff, I thought it was pretty cool how they learn techniques and how they use materials... It kinda all came together. Like how the country was coming along, then the project kinda put it all into perspective" [emphasis added]

The students also seemed to tie this activity to the concept of engineers as people who can help:

"An engineer (pause) creates or helps create something to help man" 
"Engineering is like a person who has, helps a bunch of people [laugh] like a job, there's lots of jobs, [inaudible] lots of different, they can do mathematical things and they can build things... they make stuff"

The ties between engineering and real-life applications and between engineering and other subjects are traditionally difficult to explain in the K-12 environment: this activity seemed to help cement these ideas for these students. The students seemed to use this activity to tie India (from Social Studies) to a real life disaster to engineering as a way to help. This is one of the main goals of the MEA activity.

\section{Perceptions of engineering:}

The changes in the students perceptions of engineering were drastic, although determining if this is due to the tsunami activity or the entire classroom experience is beyond the scope of this project.

Students who were already enrolled in the class seemed to have a generally accurate view of what engineers do and how they can help society. This is to be expected, since this course is a pre-engineering course taught by a well-respected teacher with a strong interest in engineering. There was a stark difference between pre-interview subjects who had started the Gateway to Technology (GTT) course and those who had not yet started it.

Every student who had not started the course, and every student who had started and were asked what they thought of engineering before the class had a perception of engineering as a physical "building" profession. As the literature suggested, most students thought that engineers were similar to construction workers or automotive mechanics:

(students who had not yet started GTT class): So what do engineers do?

"You get to work with technology and stuff, like building cars and stuff..."

"They work on cars, and things that are, like, mechanical."

(students who were already in the class) So what did you think it was before - pretend you never had this class; what do you think engineering is?

"I used to say they were guys that used calculators to calculate things"

"Just, guys with lab coats on and glasses just writing down stuff, writing notes and stuff"

"Building stuff."

"No idea... absolutely no idea... didn't know what I got into... \{laugh $\}$ I thought it was guys that worked on cars... Whoo... \{laugh $\}$ " 
"My idea used to be someone who worked under cars, and in a factory and stuff Maybe something like - has to do with mechanics - that's what I thought."

Students who had started the class but not yet completed the project had a relatively clear perception of what engineering involved:

"They design a lot of things like buildings; it depends on what kind of engineer you are. They build bridges; that helps society go from place to place..."

"I think engineers are kinda like the doctors of wood and tools. They build stuff that helps the world. They build bridges, and some of the most beautiful stuff that the world has to offer."

These ideas mirror those typically heard when talking to middle and high school students. There is a clear change in perception after the class and activity:

What do you think engineering is?

"Um, [pause] well, I think they make things a lot easier than it really is, and, um, there's a lot more to it than what I thought it was before"

OK, so what do you think, day to day, does an engineer do? What's the life of an engineer?

"You would have to create - like the ipod - you would create the nanotechnology that goes into the ipod and that - didn't you say you are electrical?"

Yeah, electrical

"The electrical engineers would have to run the ipod, and then the ... I don't know, someone else might have to do another part of the job. I don't know who would do that one part, where you spin..."

The wheel?

"Yeah, the ... mechanical would have to invent the touch thing..."

It might be electrical - there are things like touch screen monitors where you just touch them, that's an electrical thing

"Yeah. So engineers would have to work on a team, like a design team...My mom thought I'd be a good engineer because I'm so creative, I can build stuff really well, and I didn't really know what an engineer was, well, I kinda did, from previous stuff, but I never had a class like this, now I know more about the different kinds and what kind I might like to be."

"It's good to be creative that way you can show also whose designs and it can be turned into something great; you can make something really important out of a simple drawing"

"I think it was all about learning about the design process and like knowing how to do, like how to do models, you can make models of the distribution, and what it takes for people to get their job done, and it's all about like - it's such a huge design a lot of people need to work from an establishment. I know there's a lot of different types; the 
main point of being an engineer is you learn and you get to teach, and when you can show when you do something to help out, no matter what job you have, you are being an engineer. Basically a teacher, yet you are a student. Even teachers are like engineers. “

These descriptions are far more accurate and describe characteristics like design, creativity, invention and teaming that are part of the profession.

Students were asked to check one of the following options on the end of activity survey: each option is shown with the percentage of students selecting that option:

Did this activity give you a better idea of what an engineer does?

(13.7\%) yes, I never really knew what an engineer did

$(25.3 \%) \quad$ yes, I had an idea but this really cleared it up

$(51.6 \%) \quad$ yes, Engineers do more than I thought they did

(7.4\%) no, I already knew what engineers did

(2.1\%) no, This activity didn't show me what engineers could do

While the items are not necessarily mutually exclusive, students were asked to select their best single response. The majority of students selected the option indicating that engineers do more than they thought; when added with "had an idea, but this cleared it up" the total exceeds $75 \%$.

\section{Conclusion}

The National Academy of Engineering has identified a critical need to address a lack of appreciation of engineering, and institutions of higher learning are researching the need for problem solving, creativity and diversity in the field of engineering. Middle school students clearly have misperceptions about engineering, especially its relationship to society and a profession that benefits mankind.

Integrating a hands-on activity that appeals to students is one method of promoting an accurate and interesting picture of engineering as a profession, and proper integration into multiple courses allows students to see engineering as an interdisciplinary activity. The Model Eliciting Activity (MEA) format of the problem presented allows students to not only develop a solution to a global problem, but to experience the design process; this should prove helpful in the development of effective problem solving skills.

This activity - as well as any proposed classroom activity - must be tied to state educational standards to truly succeed. Teachers from different areas should work together to properly implement this or any other activity in a truly interdisciplinary manner.

The activity was very effective in helping students develop an accurate perception of what engineering, although its implementation in a pre-engineering course certainly helps to develop this perception. Student interviews showed a positive change in the perception of engineering, including the concept of engineering as a helping profession. Interviews and student surveys 
also showed that the activity was enjoyable and informative to the students. Engineering as a "helping profession" was presented successfully.

\footnotetext{
${ }^{1}$ Augustine, Norman (chair), National Academies Committee on Prospering in the Global Economy of the $21^{\text {st }}$ Century, Rising Above the Gathering Storm: Energizing and Employing America for a Brighter Economic Future, National Academies Press, Washington, D.C., 2005.

${ }^{2}$ Knight, Meredith and C. Cunningham "Draw an Engineer Test (DAET): Development of a Tool to Investigate Student's Ideas about Engineers and Engineering", Proceedings of the 2004 American Society of Engineering Education Annual Conference, (2004).

${ }^{3}$ Finson, Kevin (2002), "Drawing a scientist: What we Do and Do Not Know after Fifty Years of Drawing", School Science and Mathematics, 102(7), 335-345.

${ }^{4}$ Knight and Cunningham, et. al.

${ }^{5}$ Diefus-Dux, Heidi, M. Hjalmarson, J. Zawojewski, K. Bowman (2006) "Quantifying Aluminum Crystal Size Part I: The Model-Eliciting Activity"”, Journal of STEM Education Innovation and Research, 7(1).

${ }^{6}$ Froyd, Jeffrey (2005). Transfer of Learning: Foundation for Engineering Outcomes, Proceedings of the 2005 American Society of Engineering Education Annual Conference, (2005).

${ }^{7}$ Moore, Tamara \& H. Diefus-Dux, "Developing Model-Eliciting Activities for Undergraduate Students Based on Advanced Engineering Content", Proceedings of the 2004 Frontiers in Education Conference, 2004.

${ }^{8}$ Diefus-Dux, Heidi, T. Moore, J. Zawojewski, P.K. Imbrie, D. Follman (2004). A Framework for Posing Open Ended Engineering Problems: Model Eliciting Activities”. Proceedings of the 2004 Frontiers in Education Conference, 2004.

${ }^{9}$ Moore, Tamara, H. Diefus-Dux, P.K. Imbrie, (2004) "Developing First-Year Students' Perceptions of the Engineering Profession through Realistic, Client-Driven Problems", Proceedings of the 2004 Frontiers in Education Conference, 2004.

${ }^{10}$ Augustine, et. al.

${ }^{11}$ Project Lead the Way, URL: http://www.pltw.org, accessed 10/1/2006.

${ }^{12}$ Reid, Kenneth J. and C. Feldhaus, "Articulation Agreements with High Schools Implementing Project Lead the Way (PLTW)", (2005). Proceedings of the 2005 American Society of Engineering Education Annual Conference, (2005).

${ }^{13}$ Driscoll, Marcy (2005). "Psychology for Learning Instruction" Pearson publishers.

${ }^{14}$ Indiana Educational Standards, URL: http://www.doe.state.in.us/standards/, accessed 12/1/2006.

${ }^{15}$ Hatch, J.A. (2002). Doing Qualitative Research in Education Settings. Albany, NY. SUNY Press.
} 